\title{
GCompris: Auxiliando o Desenvolvimento da Leitura e Escrita dos Alunos com Deficiência Intelectual
}

\author{
Antônia Silvestre Evangelista de Freitas, Delfa Mercedes Huatuco Zuasnábar \\ Licenciatura em Informática a Distância -Departamento de Ciência da Computação \\ Universidade Federal de Roraima \\ Av. Capitão Ene Garcez, 2413 - 69310-000 - Boa Vista - RR - Brasil \\ yyuries@gmail.com delfa.zuasnabar@ufrr.br,
}

\begin{abstract}
The introduction of informatics as a tool of assistance in the teaching-learning process has been happening gradually in specialized care schools, and the software used in this process deserves special attention. This work presents a research using the GCompris software as a tool that helps the reading and writing development of students with intellectual disabilities applied in a case study, whose objective is to evaluate the effectiveness of the use of software in reading and writing activities in a Specialized center for the intellectual disabled. The results show improvement in learning when using the software.
\end{abstract}

Resumo. A introdução da informática como ferramenta de auxilio no processo ensinoaprendizagem vem acontecendo gradativamente nas escolas de atendimento especializado, $e$ os software utilizados neste processo merecem uma atenção especial. Este trabalho apresenta uma pesquisa com a utilização do software GCompris como ferramenta que auxilie o desenvolvimento da leitura e escrita dos alunos com deficiência intelectual aplicado num estudo de caso, que tem como objetivo avaliar a efetividade do uso do software nas atividades de leitura e escrita num centro especializado para deficientes intelectuais. Os resultados apresentam melhoria na aprendizagem quando se utiliza o software.

\section{Introdução}

Atualmente, é notável a importância da informática no cotidiano escolar e sua utilização, por meio de softwares educacionais deve ser planejado para que contribua para a aprendizagem dos alunos, inclusive aqueles com deficiência intelectual. $O$ software educacional apresenta-se como uma estratégia promissora para o uso nas escolas de atendimento especializado para auxiliar o processo de ensino-aprendizagem, que por usarem uma forma mais lúdica e agradável podem estimular uma aprendizagem dos conteúdos e habilidades dos alunos com deficiência intelectual. Estes aplicativos e jogos educacionais apoiam o desenvolvimento de habilidades como a coordenação motora, raciocínio lógico matemático, percepção visual e auditiva, memória, orientação temporal e espacial, expressão linguística, planejamento e organização.

As escolas de atendimento especializado buscam ampliar o ponto de partida e de chegada do aluno em relação ao seu conhecimento. Não se atém a solucionar os obstáculos da deficiência intelectual, mas criar outras formas de interação, de acessar o conhecimento particular e pessoal. É de caráter educacional, mas ao contrário da escola que trabalha o saber universal, o atendimento educacional especializado trabalha com o saber particular do aluno, aquilo que traz de casa, de suas convicções visando propiciar uma relação com o saber diferente do que possui ampliar sua autonomia pessoal, 
VI Congresso Brasileiro de Informática na Educação (CBIE 2017)

Anais do XXIII Workshop de Informática na Escola (WIE 2017)

garantir outras formas de acesso ao conhecimento (como por exemplo, através do Braile, Libras, uso de tecnologia, uso de diferentes estratégias de pensamento, etc.)

Deste modo, é importante ressaltar que a inclusão escolar, além de promover as oportunidades de socialização, deve também proporcionar um ambiente de ensinoaprendizagem para que todos os alunos tenham acesso ao seu máximo desenvolvimento acadêmico, competências e habilidades para que possam ser úteis em sua vida.

Neste contexto, o presente trabalho apresenta um estudo de caso cujo objetivo é verificar em que medida as atividades pedagógicas planejadas para a leitura e escrita de alunos com deficiência intelectuais, contribui para o processo de ensino-aprendizagem. Para os objetivos específicos delineamos três etapas: levantar como eram planejadas as atividades pedagógicas focadas na leitura e escrita; verificar como o aluno explicitava a apropriação do conteúdo e investigar o desempenho do aluno.

Este artigo está organizado da seguinte forma: na próxima Seção discutem-se os métodos. São apresentados os resultados coletados durante a utilização do software, na Seção 3. Finalmente a Seção 4 apresenta as considerações finais.

\section{Métodos}

Esta pesquisa foi realizada na Unidade de Capacitação e Produção "Rede Cidadania Atenção Especial" em Boa Vista - Roraima, com uma turma de 18 alunos. Com o intuito de conhecer o perfil e as características dos alunos com deficiência intelectual que seriam submetidos a esta pesquisa, foram analisados os laudos de cada um, assim como foi realizada a documentação de autorização de uso da imagem assinada pelos pais e/ou responsáveis e uma licença para aplicação da pesquisa.

A abordagem da pesquisa se deu pela investigação em estudo de caso de natureza qualitativa por descrever a complexidade da situação pedagógica, analisar e compreender processos dinâmicos vividos por alunos com necessidades educativas especiais inseridas no processo de inclusão social.

O foco da pesquisa é de natureza aplicada ao ensino e aprendizagem da leitura e escrita utilizando o software GCompris como ferramenta digital para incentivar aos alunos com deficiência intelectual a compreender e aprender os procedimentos da leitura inicial avançando as etapas conforme as condições cognitivas de cada aluno.

GCompris é um software livre que foi desenvolvido no ano 2000 pelo francês Bruno Coudoin, líder do projeto na atualidade. Teve como motivação desenvolver um software educativo de alta qualidade com uma grande quantidade de atividades para a plataforma Linux, Windows, Mac OS [Guimarães 2011]. Segundo o seu mentor, a palavra "GCompris" é um trocadilho fonético, sonoro, com o termo "J'ai compris", ou "Eu compreendo" em francês [Júnior 2009].

$\mathrm{Na}$ alfabetização é necessário ensinar as letras do alfabeto, fazendo com que os alunos aprendam a reconhecê-las, para então, posteriormente serem capazes de juntálas, formando palavras e aprendendo a ler [Rodrigues et al. 2010], neste sentido foram planejadas as aulas ao longo do semestre, os alunos foram divididos em dois grupos, um 
deles com 10 alunos que usaram o software no laboratório de informática e outro com 8 alunos que trabalhou em sala de aula usando quadro e pincel. Os integrantes do grupo que usaram o software realizaram atividades em duplas onde cada sessão tinha duração de 20 minutos.

Na primeira sessão foi apresentada a interface gráfica do software, na coluna esquerda apresentam os ícones das tarefas, ao clicar numa tarefa serão apresentadas as atividades como mostrado na Figura 1. O software contém um ícone para a tarefa de leitura como mostrado na Figura 2, ao clicar este ícone é mostrado um conjunto de atividades com áudio que são trabalhadas de acordo com o planejamento de aula, para atingir o objetivo de apoiar o processo de ensino/aprendizagem da leitura e escrita.

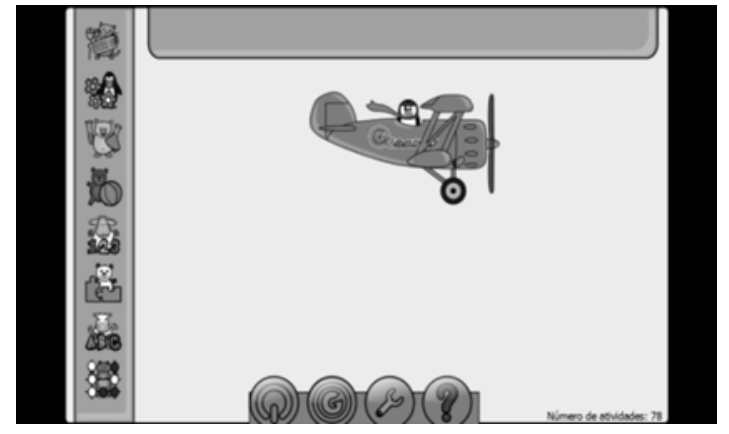

Figura 1 - Interface do software GCompris

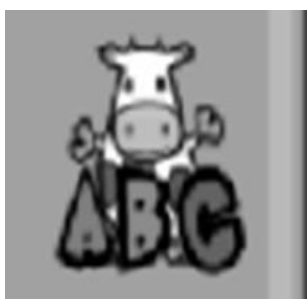

Figura 2 - Atividades de Alfabetização.

No princípio os alunos apresentaram dificuldades para aprender o funcionamento do GCompris a qual foram consideradas situações normais diante do novo contexto de aprendizagem, mas aos poucos foram se familiarizando com as tarefas e atividades construindo sua própria autonomia para a realização das atividades de leitura.

As atividades realizadas ao longo das sessões foram: Alfabeto clique na letra, jogo da memória com números por extenso, prática da leitura: palavra que corresponde à figura, a letra desaparecida: encontre a letra que esta faltando e completa a palavra, entre outras. Na Figura 3 mostra alunos utilizando o software GCompris realizando as atividades de alfabetização.
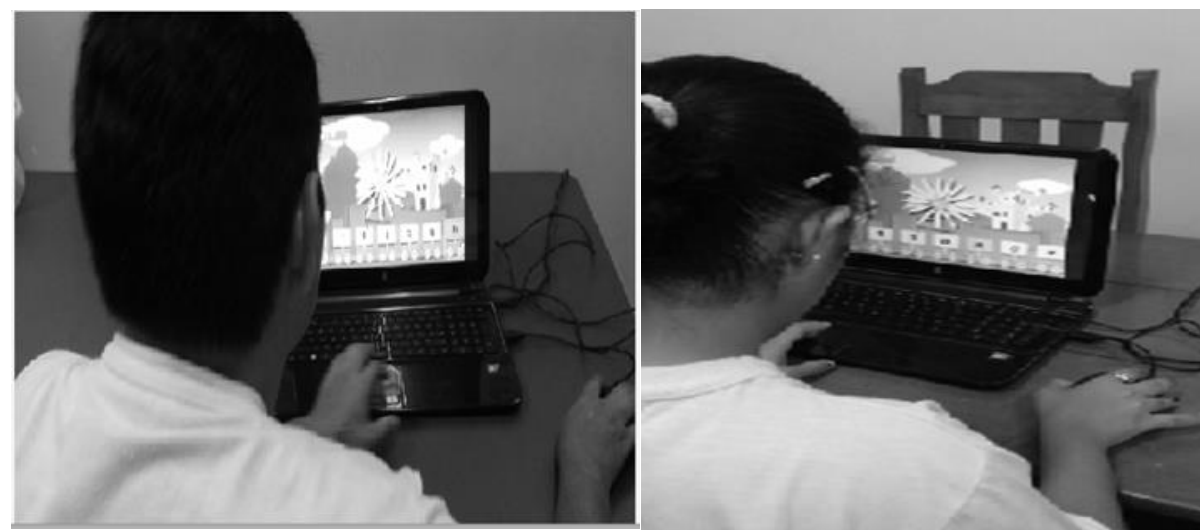

Figura 3 - Alunos realizando atividades no software GCompris. 
No conteúdo das atividades é trabalhada a tarefa da leitura de forma dinâmica por meio do software GCompris, onde o aluno recebe os estímulos para aprender de acordo com as ações solicitadas ao acertar recebe elogios, se errar tem oportunidade de outra tentativa para refazer a atividade.

Ao término de cada atividade eram realizadas leituras individuais no próprio software GCompris silenciando o áudio para que o aluno pudesse ler oralmente, também ditado de letras e palavras trabalhando a escrita, a assimilação e memorização dos conteúdos referentes as atividades de aprendizado da leitura compostas no software Gcompris comprovando a eficiência do aprendizado.

O grupo de 8 alunos que trabalhou em sala de aula realizaram suas atividades de leitura/escrita usando jogos por exemplo alfabeto móvel, jogo de formação de palavras, textos escritos para leitura, ditados de letras, palavras e textos para escritas dos alunos no quadro.

\section{Resultados e Discussão}

Este trabalho apresentou o resultado de uma prática docente vivenciada através da experiência metodológica com uso da tecnologia observando o fato surpreendente do aluno com deficiência intelectual superar dificuldades e aprender a ler e escrever incentivado com o software GCompris.

Para [Vygotsky 1987], há potencialidades e capacidades nas pessoas com deficiências, mas entende que, para estas desenvolvê-las, devem ser-lhes oferecidas condições materiais e instrumentais adequadas, com isso, deve-se oferecer as tais pessoas uma educação que lhes oportunize a apropriação da cultura histórica e socialmente construída, para melhores possibilidades de desenvolvimento.

O resultado do trabalho de alfabetização usando o software GCompris facilitou o processo de ensino-aprendizagem da leitura e escrita dos 10 alunos, sendo que o $80 \%$ aprenderam a ler e escrever com sucesso, assim como gostaram do software GCompris, por ser atrativo, motivador e dinâmico. No quesito coordenação motora, os alunos não apresentaram grandes dificuldades na utilização do mouse e teclado. Para validar os resultados de aproveitamento, foram aplicados pré-testes após as aulas sem o software, e pós-testes após as aulas com aplicação do software GCompris.

Do grupo dos 8 alunos que usaram sala de aula, 50\% aprenderam a ler e escrever e os outros 50\% não atingiram os objetivos de leitura e escrita. Para validar os resultados de aproveitamento, foram aplicados pré-testes e pós-testes após as aulas com o método tradicional.

Diante destes resultados podemos afirmar que os alunos que fizeram uso do software GCompris obtiveram melhores resultados na aprendizagem da leitura e escrita, demostrando que o software contribuiu para um reforço prático e motivador na atividade de alfabetização.

Observamos que dentro da educação especial os alunos têm ritmos de aprendizagem que são influenciados por fatores biológicos e sociais que registram a 
VI Congresso Brasileiro de Informática na Educação (CBIE 2017)

Anais do XXIII Workshop de Informática na Escola (WIE 2017)

individualidade e tempo que cada aluno precisa para avançar na aprendizagem [Souza et al 2012].

\section{Conclusões}

As atividades lúdicas que o software GCompris desenvolveu trouxe um suporte pedagógico facilitador do processo de ensino-aprendizagem de forma construtiva, as vantagens de se trabalhar com este recurso tecnológico é que outros aprendizados na sala não são menosprezados e com a mediação do software alinhado as necessidades do perfil e características do aluno com deficiência intelectual foram pré-requisitos importantes que inspiraram a realização deste trabalho de pesquisa.

A tecnologia oferece uma gama de recursos que podem ser utilizados para diminuir as barreiras, disponibilizar novas formas de interação e comunicação, e servir como ferramenta mediadora de ensino e aprendizagem [Araújo et al. 2013].

É fundamental ressaltar que no trabalho realizado com alunos deficientes intelectuais a dedicação, o amor, a paciência, são fatores muito importantes para conseguir bons resultados, pois nem sempre se consegue realizar o planejamento conforme foi organizado e definido, é necessário ter flexibilidade para compreender e receber as respostas do processo de ensino-aprendizagem.

\section{Referências}

Araújo, A. L. S. O.; Brito, R. R.; Silva, A. P. (2013) "Softwares para a educação inclusiva: uma revisão sistemática no contexto do SBIE e WIE. II Congresso Brasileiro de Informática na Educação. UFPB - PB Brasil.

Guimarães, F. G. (2011) "Sobre o GCompris", Em: GCompris. http://GCompris.net/Sobre-o-GCompris-. Junho.

http://www.educadores.diaadia.pr.gov.br/arquivos/File/maio2013/sociologia_artigos/ pesquisa_social.pdf, Junho.

Júnior, J. F. C. (2009) "Entrevista com Bruno Coudoin, criador do GCompris", In: Revista Espírito Livre. n.7. Outubro.

Rodrigues, Y. W. S.; Silva, N. G. R.; Silva, E. V.; Severo, D. S.; Diniz, F. A.; Júnior, G. M. O.; Gomes, A. S.; Alves, C. (2010). SAEPS: Uma ferramenta de apoio à alfabetização do surdo. In: XII Simpósio Brasileiro de Informática na Educação, João Pessoa, PB.

Sousa, F. R. M.; Costa, E. A. B.; Castro, T. H. C. (2012). WorldTour: Software para Suporte no Ensino de Crianças Autistas. In: XXIII Simpósio Brasileiro de Informática na educação, Rio de Janeiro, RJ.

Vygotsky, L. S. (1987). “Pensamento e linguagem”. São Paulo: Martins Fontes. 